\title{
Research on the Innovation Mechanism and Development Path of Students' Work Based on Big Data
}

\author{
Kai-Yuan LIU ${ }^{1, a}$ and Yu-Bo WANG ${ }^{2, b}$ \\ ${ }^{1,2}$ School of Journalism and Communication, Jiangxi Normal University, Nanchang, Jiangxi, China \\ a594627603@qq.com, b806690165@qq.com
}

Keywords: Big data, Students' Work, Data mining.

\begin{abstract}
Big data has penetrated into all fields of society and massive data covers a lot of valuable information, so the work of college students will be greatly affected by the impact of big data. The influence of big data on the structure of students work is the high rate of information dissemination and the high speed of arrival. Therefore, the development of the work of college students must be combined with the technology of data management, manage and coordinate the precision of the data, mine effective information deeply in the process of data collection by setting up the data collection platform between colleges and organizing professional data analysis team in colleges thus providing constructive and referential support for the reform of the existing management system in colleges.
\end{abstract}

Fund projects: This paper is the 2017 Jiangxi provincial university humanities and social sciences key research base bidding projects (NO.JD17155) results.

\section{Introduction}

Big data has penetrated into all areas of society and it has become important production factors and resources. It also plays an important role in social work and daily activities. Facing with countless massive big data in life, work and thinking, some of them are real existences, and some are hidden existences. Some of the data are what we have already found and been using, and some are still on the way of exploration or even unknown, and some are partly hidden and partly visible. In the management of college students, college student managing workers should make good use of big data, learn to interpret various data from the daily routine work, analyze timely and sort out the textured data from a variety of quantitative data for the ideological and political education services. At the same time, they must learn to adapt to this new way of information production and analyze data thus exploring a more accurate development road with high quality service and experience for the students, which will become the core competitive factors in the future of student work.

\section{The Structural Impact of Big Data on Student Work}

Big data is a revolutionary development after the cloud computing and the Internet of things in the IT industry. Alibaba President Ma Yun puts forward the idea that the future is not the era of the IT, but the era of DT which refers to the Date Technology. The influence of Big data on the work of college students can not be underestimated. The work of college students is mainly aimed at the service and support of students' study, campus life and employment, including integrating the learning resources, expanding the space for learning, improving learning efficiency, paying attention to students' physical and mental health and providing employment counseling and other specific matters. With the development of information technology, the information management has been gradually used in the management of college students. Based on the view of big data, we can find that the daily activities of the work of college students are actually the interaction and extension of mass data. The various roles and links of college student management have become the production factors of big data. The reason why the management level and efficiency of student management workers can be significantly improved can not be separated from the support of big data. 


\subsection{The Timely, Accurate and Effective Dissemination of Information.}

Information dissemination has become very timely and effective with the help of the network technology. At the same time, with the help of the information channel, the arrival of information to designated target population has become very accurate. In colleges, the specific audience of information dissemination is student. The students' subjective information receiving and screening has a certain reaction to the information dissemination. Because the big data has the characteristics of non direct contact transmission, whether the information is faithfully transmitted to the students, whether there is the "distortion" phenomenon in the virtual space in the dissemination of information, whether there are rumors that will breed in this process are the problems and challenges that need to be faced in the big data transmission for the university administrators. At the same time, in technical management of big data, due to the lack of direct communication between counselors and students, there will inevitably be some certain gap between them which reduce the face-to-face communications between students and teachers to some extent.

\subsection{Seeking Truth, Depth and Analysis of the Information Management.}

Data is not a panacea, but it does point the predictable direction of things for human beings. With the help of big data, we can find the direction and trend of development from the correlation between things. Big data also gives us a huge risk because it may leak privacy. If this happens, related techniques and the privacy protection doctrine which has the legal effect may not be helpful at all. No matter how huge a threat big data technology poses to privacy protection, the biggest problem is the impact on our thinking and behavior.

The application of the big data in the process of information management in colleges should achieve the seek of truth. The so-called "seek of truth" means managers should save electronic files in the course of the construction and service of the information of students for the comprehensive and complete retention of data. At the same time, "the seek of depth" means to dig the data deeply, and "the seek of analysis" refers to the comprehensive and objective analysis of data. The "data waste gas" mentioned in Big Data is the interactive by-product of online interaction between users, including the number of the pages while browsing the website, the length of the residence time, the position of the mouse cursor, the input of information so on [1]. Therefore, the senior management in the daily affairs of the work should learn to collect data, make specific analysis of specific issues and extract useful data out thus achieving the more effective and rapid solution to the daily routine work.

\section{The Acquisition and Application of the Big Data.}

In Big data era: big changes in life, work, thinking, Schoenberg points out that big data is not random samples, but all the data; not the accuracy, but the mixture; not a causal relationship, but the interrelation. McKinsey thinks the so-called big data means that the size of the data set involved has exceeded the ability of traditional database software to acquire, store, manage and analyze [2]. There are two main types of data in colleges. One is the structured business data which can be represented by a unified digital symbol, and the other one is the unstructured service data which has various formats and can not be represented by a unified digital symbol. The college students' work managers should build the data platform, organize the related data analysis team of experts and monitors, evaluate and integrate the data in the colleges thus carrying out the education of students and guiding the students' thoughts.

\subsection{The Acquisition of the Big Data.}

IBM points out that we can use " $4 \mathrm{~V}$ " to define big data, that is, volume, velocity, variety and veracity [3]. " $4 \mathrm{~V}$ " theory covers the most significant features of the big data. The first one is its huge volume of data. The traditional software can't manage, extract and analyze the big data for its huge scale. Meanwhile, if you want to store such a huge data, a new technical system is needed. The second feature is the variety of data types which can be embodied from the fact that the data can be 
divided into common structural data and other unstructured data with pictures and videos. The third one is its velocity which means the level of technology which data reach based on cloud computing and other technical support. As for the veracity, some scholars point out that it refers to the value of the data which can discover and summarize the new law for the university student management work.

College students tend to use the campus network where they do some social activities in daily life including video communication, e-mail, web browsing. These data can reflect college students' ideological trends, emotional status and learning state. According to the thirty-seventh China Internet network development status statistics report released by CNNIC, as of December 2015, China's Internet users reached 688 million, Internet penetration rate reached 50.3\%, which means that nearly half of the Chinese people began to access the Internet among which the size of mobile Internet users reached 620 million. Nowadays, the popularity rate of Internet users among college students is very high and almost all of the college students have a mobile phone. Socializing, shopping, and learning through mobile phones have become the norm. College students work managers should collect the data of students' calls, consumption, and web browsing through the Internet and mobile terminals in time, analyze and classify the data so as to find what students care about and what they are interested in for targeted teaching and instruction. At the same time, schools should set up the coordination department as well as the data center and guarantee to collect all the data of all students which include the basic data of students when registering and the sum of all kinds of browsing data during school days.

\subsection{The Application of the Big Data.}

Under most circumstances when facing students' attendance, staying out late, staying out all night, conduct points, comprehensive assessment, and grades, a small part of these data were used even though they are all organically connected and inseparable. Managers only notice the phenomena of staying out late and staying out all night but hardly analyze and investigate the reasons in order to take specific measures to solve fundamental problems such as the safety problem.

Big data can not only improve the efficiency of student management work but also build up a special system of higher education teaching. For example, many of the world's top colleges and universities open online courses which can help students around the world to enjoy the same quality education. Massive Open Online Course (MOOC) is a new form of online courses based on curriculum and teaching theory as well as the network and mobile communication technology. Compared with the previous online courses, it increases the "interaction", "mutual assistance", "behavior evaluation and guidance" and other new technologies. Through a variety of data analysis methods, MOOC can summarize the characteristics of learners, predict the content and form of teaching which learners need next thus implementing studying according to the demands of students and teaching according to their ability [4].

\section{The Development Path of Students' Work under the Background of big data.}

Big data has a large capacity of information and various transmission forms, and the most important feature of it is its non-contact information dissemination and its high information arrival rate, so the authenticity of the information identification also needs to be carefully considered. Based on the characteristics of the development of the era of big data, the work of college students should start from the following aspects. First, we should strengthen the awareness of using the data in college students' management and universities should strengthen the combination of technology and build a data platform. Second, expert teams of data analysis should be organized in colleges and universities. Third, we should establish a data management system and develop big data technology jointly.

\subsection{Strengthen the Sense of Data Management and Establish Data Platform Jointly.}

When facing the new form of student information collection and management in the era of big data 
differing from the previous single oriented one, managers of students' work in colleges should strengthen their awareness of data. The basic necessities of life, the emotions, and the activities of students exist in the form of data.

In colleges, integrated comprehensive evaluation work should be all-round. Big data can help college management team make more accurate evaluation of students compared with the previous channel of understanding and cognition of students. By collecting the basic information of the target including the personal growth path, the learning state of each phase, and the general situation of family education, college management team can evaluate a student's comprehensive quality in a short time. Data acquisition path requires colleges and universities to build data platform. Students in colleges often do some social activities on the Internet and some of their basic information exists on the Internet in the form of data. If universities do not pay attention to the leakage of students' information, it can cause very serious problems. Therefore, universities should strengthen management and standardize the process of data mining and analysis. Moreover, because of the problems of the relative advantages between colleges, schools and enterprises should unite and complement each other to invent applications related to data analysis. This will both improve the school talent quality and achieve the common development of the high school.

\subsection{Improve the Ability of Data Integration and Organize Professional Data Analysis Team.}

University data types are divided into three categories including scientific research data, network data and sensor data. Professional data team should be established to analyze and evaluate data because of big data's large carrying capacity and trivial content. It can be predicted that the shortage of senior data analysis talents will become more and more prominent in the next few years [5]. The scarcity of data analysis talents is not only reflected in various departments of the colleges. There are data which also show that senior data analysis experts have a lack of nearly 200 thousand in the U.S. Market.

Data analysis team in colleges and universities should be able to understand the relationship between the various departments of the school. At the same time, they should be able to solve the various problems of college students that may arise according to the analysis of big data. From a macro point of view, the improvement of the ability of data integration is conducive to the timely development of management policies in colleges and universities. From a microscopic point of view, the ability of data integration can play an indispensable role in improving the management level, efficiency and innovation of colleges. For example, Nanjing University of Science and Technology provides subsidies for specific students by retrieving the consumption of their meal card. The acclaimed "precision aid" provides subsidies through the analysis of consumption record of the meal card which can not only protect the self-esteem of the impoverished students but also explore a new direction for the development and management of the school.

\subsection{Establish a Data Management System and Develop Big Data Technology Jointly.}

The application of the big data technology has its advantages and disadvantages. The managers of the college students' work should establish the corresponding management system to the big data technology and carry out targeted supervision and management in the collection, monitoring and analysis of the data.

Because the student's data is open, sometimes it is inevitable to bring some unnecessary trouble on the security issue. Data such as students' personal privacy, preferences, personality characteristics, and family information are controlled by counselors. The large capacity of data increases the possibility of the exposure of sensitive data and the disordered use of the data also increases the risk of information leakage [6]. As student affairs workers, what should we do to these important data?

First of all, managers should protect students' personal privacy including the preferences, personality characteristics, family information and telephone numbers. There should be fixed places and necessary equipment to store students' files and other data. In addition, managers should take record whenever they talk to students. When there is a need to update students' information, 
managers should update the data in time in order to provide convenience to solve the problems which may arise in the future. Third, if students and parents question the security of the personal data, the counselor should accept the question and make explanations so that students and parents can understand the benefits of the correct data.

\section{Conclusion}

In the past, students' work in colleges and universities relied on the experience and there was a certain lag. In big data era, through the combination of the qualitative and quantitative analysis of information technology, managers can provide students with more timely work and high quality support and services. Big data has a significant and far-reaching impact on the development of human society. The long-term development of student management can not be separated from the application of the big data. But we need to realize that big data is only a technical means. It is not a ready-made panacea to solve all problems. Therefore, in the daily management work, we should not only update data but also update our management and service level. We should do the students' work with our true heart and true data.

\section{Literature References}

[1] Viktor Mayer-Schönberger, Big Data [M], Zhejiang people's Publishing House, 2002, pp. 144-159.

[2] Manyika J, Chui M, Brown B, et al. Big data:The next frontier for innovation, competition, and productivity [Z], Technical report, McKinsey Global Institute, 2011.

[3] Zhao Guodong, Yi Huanhuan, Mi Wanjun, et al. The historical opportunity in big data era -industrial revolution and data science [M], Beijing: Tsinghua University press, 2013: 21.

[4] Zhang Yu, Li Yue, The introduction of learning analysis and educational measurement based on MOOCS [J], Research On Education Tsinghua University, 2013, 34 (4): 22-26.

[5] Tao Xuejiao, et al. A summary of the research on large data (J). Journal Of System Simulation, 2013, (25).

[6] Feng Wei. Information security opportunities and challenges in the era of big data [J]. China Venture Capital, 2012, (34) 